InOedia $\quad \begin{aligned} & \text { InMedia } \\ & \text { The French Journal of Media Studies }\end{aligned}$

8.1. $\mid 2020$

Ubiquitous Visuality

\title{
Experiencing, Experimenting with, and Performing Visual Narratives
}

Large- and Small-Scale Stories in AAA Action-Adventure Game Franchises

\section{Clémence Folléa}

\section{(2) OpenEdition}

\section{Journals}

Electronic version

URL: http://journals.openedition.org/inmedia/2031

DOI: 10.4000/inmedia.2031

ISSN: 2259-4728

Publisher

Center for Research on the English-Speaking World (CREW)

Electronic reference

Clémence Folléa, "Experiencing, Experimenting with, and Performing Visual Narratives", InMedia [Online], 8.1. | 2020, Online since 15 December 2020, connection on 28 January 2021. URL: http:// journals.openedition.org/inmedia/2031 ; DOI: https://doi.org/10.4000/inmedia.2031

This text was automatically generated on 28 January 2021

(C) InMedia 


\title{
Experiencing, Experimenting with, and Performing Visual Narratives
}

\author{
Large- and Small-Scale Stories in AAA Action-Adventure Game \\ Franchises
}

Clémence Folléa

1 While videogames have the means to create uniquely new narrative experiences, ${ }^{1}$ they also repeatedly borrow from other popular forms of visual storytelling. This is especially true of "AAA" videogames, ${ }^{2}$ which repeatedly rely on the aesthetics and techniques of TV series and filmic blockbusters, thus also seeking to appeal to their wide audiences. Indeed, in the AAA industry, technological innovation is often continuously channelled into the making of long-running stories and immense spectacular storyworlds, rather than the refining of a specifically interactive form of narration. As a result, when compared to the more innovative trend of contemporary independent games, AAA games are often frowned upon as exceedingly low-risk standardized productions. Indeed, few AAA games of the 2010s sought to challenge their users' expectations with innovative modes of storytelling or original gameplay mechanisms; instead, in order to secure a wide audience, they often repeated the same formula of providing users with visually impressive and immersive storyworlds, as well as with linear and teleological narrative structures likely to meet expectations derived from the other commercially successful contemporary forms of visual storytelling like TV series and Hollywood cinema.

2 Thus, this article seeks to question how AAA videogames rely and/or innovate upon other modes of visual storytelling. It takes up on an ongoing effort in the field of videogame studies to detect and investigate potentially fruitful "correlations between the ludic phenomenon and the narrative phenomenon" and thus to "bring forth new research perspectives" on both. ${ }^{3}$ The present article focuses more particularly on action-adventure franchises, such as Ubisoft's Assassin Creed, Naughty Dog's Uncharted, and BioWare's and Electronic Art's 2007-2012 Mass Effect, ${ }^{4}$ where short gameplay challenges (such as shooting enemies, negotiating difficult paths, or solving puzzles) combine with the unfolding of a long-running narrative, often supported by 
spectacular and/or photorealistic graphics. These games' large-scale overarching plots rely on immersive "cinematic" sequences to advance the story, and encourage players to relentlessly move the avatar forward, accumulating power, overcoming obstacles, and carrying the narrative trajectory towards its goal. However, this article will also show that, while these commercial games remain structured by the linear and teleological patterns inherited from traditional modes of storytelling, playing them can also offer a disrupted experience of linearity. I will, thus, endeavour to show how gameplay sequences can be viewed as small-scale stories, which temporarily obscure or even clash with the large-scale narrative framework scripted by developers.

\section{Remediating serial storytelling in action-adventure franchises}

3 Videogames' large-scale and immersive storyworlds first emerged in the 1990s, when technological innovations such as floppy discs and, later, CD-ROMs made it possible for developers to include more data in their games. Whereas games had previously offered more or less brief and repetitive sessions of shooting at enemies for no outstanding narrative reason, better storage capacities now allowed them to supply players with a longer and more developed logic of progression. Nowadays, immersion into storydriven games can go on for dozens of playing hours, and is also very often prolonged by an abundant number of sequels. Thus, many AAA action-adventure games continue into highly profitable series, whose level of narrative coherence varies depending on the franchise. In some cases, as with the ongoing Assassin's Creed series, developed and published by Ubisoft, stand-alone games are remotely linked together by a loose plotline. Other franchises, such as BioWare's and Electronic Art's 2007-2012 Mass Effect trilogy, adopt a format closer to that of the serial, unfolding their plots from beginning to end over a sequence of several episodes. Whatever its format, the now widespread franchise model is a relatively low-risk and efficient way for these big-budget games to ensure profitability. Here, videogames resort to a long-established strategy, repeatedly adopted in the past for maximising the consumption of stories: "as new media technology is introduced commercial exploiters have consistently turned to the serial form of narrative presentation precisely in order to cultivate a dependable audience of consumers." ${ }^{5}$ Great franchises of AAA games, like serials, are indeed part and parcel of a culture industry whose most salient interest is in perpetrating itself by maximising consumption/profit and, as a result, standardising production.

4 Nevertheless, as Jennifer Hayward puts forward in her landmark study of literary, television, and comic serials, "such an argument allows little room for the audience." 6 While these long narratives are certainly mass-produced, commercially driven, and are therefore relatively standardised, they also possess inherent traits that encourage their audiences to be more than just passive consumers. Indeed, while serial productions certainly cater to "the most traditional expectations of storytelling," their longrunning plots, vast storyworlds, and large casts of characters result in a "lack of traditional closure, dispersed plot strands, [and] multiple points of view," ${ }^{8}$ inviting audiences to engage in an active exploration of their multi-layered narratives. Hayward, thus, demonstrates that serial fiction favours users' inputs in the shape of extra-diegetic interactions, such as the "demands" addressed by contemporary readers to nineteenth-century serial authors or the very active "computer network discussion 
group" conducted by soap opera fans. ${ }^{9}$ Franchises of action-adventure games not only possess the same multi-layered quality and active fan communities as the literary and visual serials studied by Hayward; they also offer fictions which are designed to be inherently interactive, thus, potentially engaging an even more active audience than other serial media.

In videogames, the moving images that make up the story on the screen are activated, shaped, and ordered by the user's inputs, as interaction is supposed to be an essential part of the narrative experience. Players of contemporary action-adventure video games expect to be involved in the development of the story, whose plotlines should activate and transform according to their own actions. Therefore, action-adventure games often invite players to make decisions that can either affect the development of the narrative, transform the storyworld, or alter the characterisation of their own avatar. Such games offer a form of interactivity which Marie-Laure Ryan calls "internal-ontological" since the "user impersonates and sometimes creates an individual member of the storyworld" ("internal") and "her actions [...] cause events that bring lasting changes" to this world ("ontological"). ${ }^{10}$ While Ryan's definition broadly characterises a large amount of AAA action-adventure games, the degree of influence which the player can exert on the story's development varies greatly from one franchise to another.

\section{Degrees of interactivity in video games' large-scale stories}

Some AAA action-adventure games frankly engage the player in narrative corridors, with few possibilities for digressions or "side quests." Game designer Raphael Chandler calls this type of design "logocentric," defining it as "linear and controlled and [having been] plotted out and documented by the designer." ${ }^{11}$ Such design displays little ambition for narrative innovation as it explicitly limits the possibilities for digression and exploration. Thus, for example, the games of the Uncharted franchise (developed by Naughty Dog, 2007-2017) offer only one version of their adventure. The player can exert no influence on the development of the narrative, which follows a traditionally linear pattern: we must move from one spectacular part of the storyworld to the next by completing one gameplay challenge after another. Throughout, numerous "cut scenes" or "cinematic sequences"-during which players become viewers as the images on the screen temporarily stop being interactive-underline the important steps of the story's progression. Even our physical progression in the storyworld is heavily guided at all times by impassable obstacles blocking the "wrong" ways and by visual artefacts clearly signalling the "right" direction.

7 Open-world action-adventure games like those of the Far Cry or Assassin's Creed franchises (both developed by Ubisoft and both ongoing) provide a slightly broader array of narrative choices, giving the player more freedom of exploration and offering her the possibility to undertake different types of missions. On the one hand, some of these games' missions constitute stages in the development of the main plot: these must be performed in a certain order so as to eventually form a coherent narrative trajectory, which is as linear as that of the Uncharted games. On the other hand, the Far Cry and Assassin's Creed franchises repeatedly offer the possibility to embark on optional side quests, which lead the avatar to explore the game's vast storyworld: these can be 
conducted in various sequences and in different ways, thus, creating the impression of freedom. However, the action and choices performed during these side quests never affect either the games' overarching narratives or the franchises' loose plotlines. Indeed, with Assassin's Creed especially, Ubisoft uses cutting-edge technology to create spectacular storyworlds, but not to produce multi-layered and protean narrative experiences which would include several versions of the storylines that adapt to users' choices. As a result, these games belong to a subcategory of Ryan's "internalontological" interactivity, which she defines as "vector with optional side branches". ${ }^{12}$ In such fictions, users may stray from the central storyline but must inevitably return to it in the end. From a narrative perspective, players are certainly active insofar as they can explore optional "dispersed plot strands," ${ }^{13}$ but their implication is limited since they can never shape their own version of the game's overarching plot, whose structure remains traditionally linear and teleological, with a well-defined beginning, a middle, and an end towards which the player must relentlessly progress.

Other AAA series of games endeavour to offer more than a single version of their largescale story, relying for instance on arborescent structures. The Mass Effect trilogy (BioWare, 2007-2012), for instance, presents itself as a dynamic story tree, offering radically different narrative experiences based on the player's actions. Throughout the series' three titles, and during hundreds of playing hours, users are invited to control a human avatar called Commander Shepard and to make increasingly complex and highstakes decisions in an effort to save the galaxy from a race of synthetic beings, choosing friends, allies and enemies, saving some and abandoning or betraying others, and, thus, gradually determining the development of a supposedly personalised narrative progression. This makes for an intense immersion experience, as players feel like they are making difficult and meaningful decisions, building their own version of the protagonist and his/her story. ${ }^{14}$

9 After five years of such heavy narrative immersion, players of the Mass Effect trilogy were expecting an intense experience of closure when the third and final part of the main series came out. The multiple-choice ending was deemed satisfactory by some players, with one reviewer underlining for instance "how exciting it was that decisions [he had] made five years ago were having an impact on the story [he] was being told now." ${ }^{15}$ However, for a large number of players, the ending of Mass Effect 3 fell short of their own involvement in the narrative, as it offered a choice between a good, a bad, and a tepidly medium ending that was perceived as simplistic and seemed to render all the previous narrative complexity and interactivity all but artificial. As a disappointed reviewer puts it, the trilogy's final choice "only determines the primary color and some other minor details of an ensuing cutscene," so that the ending "undercuts the importance of choices made in this and previous [Mass Effect] games." ${ }^{16}$ The disappointment and outrage voiced by many fans eventually led BioWare to issue a downloadable Extended Cut pack in 2012, providing an alternative final choice as well as additional content fleshing out all the possible endings. Here again, video game franchises walked in the steps of traditional literary and visual serials, responding to their audiences and shaping their narratives based on users' demands, even beyond the interactivity originally coded in the diegesis.

But the narrative disappointment loudly voiced by many fans of the Mass Effect trilogy seems, in fact, inevitable: for the user to be able to shape her own version of a coherent and satisfying story, an infinity of narrative strands would have to be written and 
coded into the game; but, as with the Far Cry and Assassin's Creed franchises, technological and economic limitations inevitably lead the game's "dispersed plot strands" ${ }^{17}$ back to a limited number of narrative paths and an even more limited number of endings. Thus, while the marketing designed for the Mass Effect trilogy heralded an innovative and genuine form of narrative involvement, the game eventually had to tie up its large-scale arborescent story with an authoritative moment of closure. In the end, the game seemed to have undermined the user's influence over the development of the story and to have fallen back on a frustratingly traditional linear and teleological structure. The outcome of this trilogy is symptomatic of the limitations ultimately imposed on the narrative involvement of videogame users. Like serial fictions produced by other media, AAA action-adventure franchises sooner or later impose their own version of the main narrative, thus, compromising their interactive quality and giving users the impression that their active involvement in the unfolding of the story was all but illusory. Even in arborescent games like Mass Effect, which specifically claim to adjust their large-scale and long-running stories based on players' actions, the possibility for a truly interactive experience eventually stands out as profoundly limited.

\section{The anti-interactive effect of remediating cinema}

11 According to the negative reviewer of Mass Effect 3 quoted above, the disappointing quality of the game's ending is evidenced in a "cutscene," which barely changes according to the player's final choice..$^{18}$ As mentioned at the beginning of this article, spectacular and immersive "cutscenes" or "cinematic sequences" pepper the play experience offered by many contemporary AAA productions, where they are often used to advance the plot but also, even more prominently, to display the game's eyecatching graphics. In the past two decades, stunning designs have indeed been amongst the most prominent selling points of AAA games, as new technologies have made it possible for developers not only to tell longer stories but also to show them in a more film-like manner. Starting with CD-ROMs and 3D graphics in the 1990s, a continuous string of innovations has led studios to compete for players' attention by offering compelling visual experiences worthy of Hollywood's most spectacular blockbusters. By using computer-generated imagery (CGI) to create film-like spectacular and/or photorealistic environments, the medium of videogame "remediates" cinema, as it "appropriates the techniques, forms, and social significance of other media and attempts to rival or refashion them in the name of the real" ${ }^{19}$ : with their impressive film-like graphics, AAA games aim at attracting a wide audience hungry for the immersive spectacles of contemporary mainstream cinema.

However, by offering such film-like forms of immersion, these games also reduce their users' involvement in the play experience. Indeed, the cutscenes, where these impressive graphics are displayed, come with a complete suspension of interactivity, temporarily making the player into a spectator of the narrative's progression. The simple technological reason for this is that image resolution can be higher in prerendered sequences than during interactive sequences, when much storage capacity is needed to manage the player's interactions with the game. As a result, games containing cinematics present their users with two different levels of image resolution - although with new technologies studios are now coming closer to bridging this gap. ${ }^{20}$ 
While the movements of the frame are controlled by the player during gameplay sequences, cutscenes offer a more aestheticized configuration of the images on the screen. When playing, the user often moves the frame erratically, since her control of the perspective-whether in first- or third-person point of view-is immediately guided by her reaction to the storyworld, be it curiosity, fear, panic, etc. On the contrary, cinematic sequences "usually follow the framing and editing conventions of mainstream film-sometimes starting with longer, 'establishing' shots, for example, to provide initial orientation before moving to close-ups on important details-and mark a break from moments of more active gameplay." ${ }^{21}$ Cutscenes are therefore film-like not only because they seek to emulate cinema through spectacular and/or photorealistic CGI, but also because they resort to cinematic aesthetics and temporarily place the player in the position of a spectator. This necessity for the user to shift her immersive posture is often made explicit through the technique of letterboxing, which artificially reduces the ratio of the screen to increase its cinematic aspect, thus signalling to the player that she has now become a viewer and will not be required to perform any actions until the cutscene is over.

While videogame users are perfectly capable of switching back and forth between two immersive postures, the sheer accumulation of cutscenes in AAA action-adventure games seems to have made a dent in the interactive quality which is supposed to be at the heart of the player's experience. Thus, while the end cutscene of Mass Effect 3 has been decried because it seemed artificial in the context of this highly personalised story, it is also symptomatic of a more general tendency in early twenty-first-century AAA narrative games to take the controller away from the player. Very recently, more powerful computers have allowed studios to render cutscenes "in-engine," that is to say using the same graphics engine as for interactive sequences. As a result, cinematic images now have the same visual resolution as gameplay images, and often include some amount of interactivity-during such sequences, the player can usually move the avatar's head to look around and can sometimes also walk around within a limited perimeter. However, while this technique preserves the continuity of the visual experience, it only seemingly preserves that of the interactive experience, since the possibilities for interaction are in fact drastically restricted. During such sequences, the player must largely relinquish her active stance, momentarily resolving to exert no influence whatsoever on her progression. Once again, by laying emphasis on the spectacular film-like quality of the images displayed on the screen, such games hinder the interactive quality of their large-scale stories.

Consequently, many critics and reviewers ${ }^{22}$ continue to complain that AAA games, by using strategies and aesthetics borrowed from traditional forms of storytelling like serials or mainstream cinema, compromise the core specificity of their medium. Whether they are displayed "in-engine" or in pre-rendered cutscenes, the Hollywoodlike spectacles that constitute these games' stories often come at the cost of their interactivity. Similarly, whether they are arborescent or vector-shaped, the narrative structures of action-adventure games seem inevitably destined to disappoint by revealing the superficiality of the player's active involvement in the story. As is exemplified by the ending of Mass Effect 3, providing a coherent story and a satisfactory ending-i.e. one likely to meet traditional expectations of visual storytelling-seems incompatible with the possibility for the player to truly involve herself in its construction. As writer and game designer Greg Costikyan puts it, there seems to be "a direct, immediate conflict between the demands of story and the demands of a game. 
Divergence from a story's path is likely to make for a less satisfying story; restricting a player's freedom of action is likely to make for a less satisfying game." ${ }^{23}$ While this difficult relationship between interactivity and storytelling is often a central preoccupation for game designers and some players, it has also proved important for scholars in the field of game studies, albeit in a more contrasted way At the time of its emergence, in the mid-1990s, the field was initially structured around an opposition between "ludologists, a camp committed to games as a unique medium of play, and narratologists, a group that sees games as one in a long line of media constructed around the delivery of stories." ${ }^{44}$ However, this opposition soon moved "away from an irresolvable binarism," ${ }^{25}$ and has now become a difference in focus rather than a disagreement. ${ }^{26}$

\section{The gains and losses of remediation}

But such preoccupation with defining and preserving medium specificity is not unique to videogames: while contemporary AAA games are being accused of, or praised for, appropriating techniques from other visual storytelling media, especially film, cinema itself has long evinced its "hunger to devour and digest and change antecedent arts." 27 As is the case with games, film has often been under attack for importing non-specific features from other media. Thus, for instance, film scholar Will Brooker suggests that the presence of cinematic sequences in contemporary videogame is comparable to that of inter-titles and, later on, sound dialogue in early cinema. ${ }^{28}$ Indeed, as early as the 1920 s, the introduction of verbal signifiers into cinema's visual representation was decried as an "encroachmen[t] on film" and "a reinfestation of film by literature." 29 Similarly, contemporary critics and scholars stress that, by importing film-like features into its interactive representation, videogames absorb a form of visual immersion that differs from and therefore threatens its specific essence. As Richard Bolter and David Grusin have demonstrated about digital media, ${ }^{30}$ and as Kamilla Elliott has shown about film, such processes of cross-fertilisation necessarily accompany the development of new technologies of representation and storytelling: for the most part, "verbal/visual" media are "hybrid" 31 and the specific essence of any new medium is soon diluted by the introduction of signifiers and immersive postures borrowed from other media.

Nevertheless, Elliott also underlines the artificial and jarring quality which can result from such processes of hybridisation, when they are carried on uncritically and mechanically. Thus, for example, she observes how "BBC literary adaptation [produced] before the mid-1990s" mechanically import their source novel's words, literally transferring them into stilted dialogue and voice-overs which stick out as literary or stage-like elements, while "cinematography, videography, and sound" only play second fiddle in the representation..$^{32}$ The result is a state of "arrested aesthetic developments, caught between literature, theatre, and film, and frozen at the midpoints of the interart analogy that makes adaptation a performed filmed reading." ${ }^{33}$ Videogames offer a similar case of productive but possibly risky cross-fertilisation. With their film-like spectacles, contemporary AAA games engage a very wide audience in an intense visual experience. Combining this with serial-like length and complexity of plot, these franchises are able to offer stories of immense magnitude and great immersive power. Nevertheless, the more these games focus on the creation of such satisfying large-scale stories, the further they reduce the possibilities for digression, free exploration, and 
genuine narrative involvement. As game designer Alexis Kennedy explains, developers have yet to learn how to navigate this fine line between interactive and traditional forms of storytelling: "[n]on-linear stories work like and unlike linear stories. We're still learning the unlike things that make them work." ${ }^{34}$ This process of remediation is currently being negotiated more radically by the creators of independent games, such as Kennedy's own Fallen London for instance. As it is, AAA productions have barely started taking up these experiments: by and large, the videogame industry has channelled technological innovation into the creation of immense, photorealistic, and spectacular storyworlds, rather than into the making of original and challenging narrative experiences. For now, while these games' large-scale narratives can be as gripping as serials or as spectacularly immersive as blockbusters, they remain continuously disappointing to players seeking innovative forms of interactive fictions.

\section{Video games' small-scale stories: focusing on action at the expense of adventure}

17 However, these large-scales stories are not the only narrative experiences that players have access to in videogames. In AAA action-adventure games in particular, users constantly have to navigate between following an adventure, whose development is scripted and occurs linearly through cutscenes, and performing actions that condition the progression of the story. This back-and-forth movement between two kinds of experiences is in fact common to many story-driven games, as is explained by Geoff King and Tanya Krzywinska:

Narrative content in games [...] should be considered at both larger and smaller scales. Games of progression usually have an overarching story framework, a broad outline into which local detail is fitted. [...] the story arc moves in and out of focus during the completion of game tasks. [...] The extent to which the larger story remains 'in play' varies from one game to another. ${ }^{35}$

In the Mass Effect trilogy for instance, the main narrative revolves around the protagonist's endeavour to save the galaxy. In order to progress through this largescale storyline, the player has to accomplish several missions, during which she finds herself in various delicate situations, such as fighting enemies, penetrating closed spaces, or rescuing allies. Although these "game tasks" are linked to the "overarching story framework," ${ }^{36}$ they can nonetheless eclipse it momentarily, as the player focuses on her immediate reactions to stimuli shown on the screen. Similarly, the Assassin's Creed franchise rests on a loose plotline depicting a centuries-old struggle between two ancient factions, the Assassins and the Templars; with every new instalment, a presentday avatar is sent back into a different historical period, taking the appearance of one of his ancestors in order to acquire artefacts for the Assassins' faction. But this overarching narrative remains very much in the background during the play experience, which is centred instead on the avatar's immersion into the specific historical period, with focus placed on stealth, free-running, and occasionally combat. Thus, as the player is focusing on action, brutally fighting city guards, discretely infiltrating the Bastille, or nimbly climbing to the top of Big Ben, the game's main adventure, or narrative framework, becomes but a distant background.

Even with heavily linear games, like those of the Uncharted series, the progression is always conditioned by the completion of tasks which are likely to capture all of the 
player's attention. Arguably, each of these local gameplay challenges forms a smallscale narrative experience in its own right, momentarily eclipsing the main story. Let us consider a gameplay sequence from an Assassin's Creed game for instance: the player sets out to climb the city's highest building, which will allow her to unlock a map in her inventory. On her way, she encounters enemies, whom she chooses to run from, rather than fight, nimbly dodging them and then moving from one hiding spot to the next. But as a result of this detour, she loses her way and has to retrace her steps. Now impatient, she misses a jump and falls spectacularly down from the rooftop on which she was running. Just before hitting the ground, she grabs a window sill at the very last second. In the end, when she eventually manages to climb the building and unlock the map, the player has gone through a small-scale narrative experience which was entirely shaped by her own actions. At this point, the struggle between Assassins and Templars that constitutes the franchise's main narrative very much plays second fiddle, as the player is fully immersed in a different and more localised story.

Nevertheless, it should be noted that, although they are highly interactive and personalised narrative experiences, these small-scale stories are themselves not less linear than the large-scale plots that structure action-adventure franchises. As King and Krzywinska put it, "[c]ause-effect relationships and linear progression [...] are found in much of the detail of gameplay (certain 'causes,' such as being attacked by a monster, can have obvious 'effects' such as killing the player's avatar [...])": ${ }^{37}$ even though the small-scale stories emerging from gameplay tasks rely heavily on user's input, they are still always based on a linear pattern of cause and effect, which ultimately corresponds to what Hayward calls "the most traditional expectations of storytelling." ${ }^{38}$ Scholars like Marie-Laure Ryan or Torben Grodal have stressed how many postmodern and deconstructionist thinkers blindly erected "interactivity into the object of a theoretical mystique," ${ }^{39}$ welcoming digital media as a means to emancipate us from "a Western, metaphysical logos-thinking (e.g., causality)" 40 of which linearity is a symptom. Nevertheless, as Grodal underlines, digital games based on action and performance cannot possibly achieve nonlinearity, since "[a]n experiential flow is-unless totally unfocused-a linear process in time," always governed by patterns of cause and effect. ${ }^{41}$ The completion of a gameplay task, even if it results in a highly personalised narrative experience, must always unfold linearly, as do the stories told in literary serials and shown in cinematic blockbusters. In addition, the gaze of the gamer is always teleological, as it necessarily focuses on a goal which must be achieved through a series of steps. As game scholar Barry Atkins demonstrates in "The Future-Orientation of Video Game Play," videogame users always apprehend images on the screen "as a matrix of future possibility." ${ }^{42}$ This is true in more ways than one. Indeed, not only are players constantly working towards a goal to achieve, be it on a small or on a large scale, they are also "voracious in [their] demand for a novelty of visual experience." ${ }^{43}$ Thus, with their scripted narrative, their innovative photorealistic spectacles, and their goal-focused gameplay challenges, AAA actionadventure games seem to necessarily structure their player's immersion in heavily linear terms. 


\section{Game vs play, progression vs repetition}

Nevertheless, the analysis of these games-their narrative trees, their graphics, their gameplay mechanics-is not enough in order to understand the play experience they offer. As Mathieu Triclot advocates in Philosophie des Jeux Vidéo, "game studies" should always be completed by "play studies," for the experience of playing a game cannot be summarized by merely describing this game as an artefact. ${ }^{44}$ Studying the play experience of AAA action-adventure games in particular can lead us to uncover specific innovations upon traditional narrative constructions and experiences. Indeed, although these games are structured on small and large scales by linear patterns, they offer a much-disrupted experience of linearity. First, it should be emphasized that the experience of playing such games is one of intense bodily immersion. As Grodal puts it, with action videogames, "not only are we able to see and feel, we are even able to ACT upon what we see in light of our concerns, our (inter)active motor capabilities allow us to shoot at what frightens us or approach what activates our curiosity." 45 Despite the presence of cutscenes, which temporarily turn the user into a viewer, the play experience remains one of bodily engagement and participation: during gameplay sequences, the player must react to visual and oral stimuli, and she does so through kinaesthetic implication. The player's linear progression thus takes the shape of an active performance, as she presses buttons on her keyboard or controller with necessary eye-hand coordination in order to cause effects that will help her towards a goal. This creates a type of immersion into images and narratives which is extremely specific to videogames.

Moreover, this intense experience seldom results in the smooth and uninterrupted achievement of a linear progression. Indeed, while the player must successfully perform actions in order to advance in the gameworld and in the narrative, she is often unsuccessful in her performance, and must take her avatar through a cycle of dying and retrying before moving on to the next stage of her progression: when the player misses a jump or fails to defeat an enemy, for instance, the avatar dies and the game is resumed at the point where it was last saved. Many action-adventure games even include a specific feature which anticipates this experience of disrupted progression: often, a key on the controller is assigned to a "quicksave" function, which allows the player to save her progression without the trouble of going through the menu; this enables her to save her game regularly, in anticipation of the many times when her linear progression will be interrupted by failure. Additionally, another key is assigned to a "quick load" function, which opens up the possibility of seamless repetition. According to Triclot, the "quicksave/quickload" feature forms "the core of a specific experience, linked with the computer technology" on which this medium depends. ${ }^{46}$ Some players-often self-defined as "hardcore," i.e. more dedicated and therefore more skilled than "casual players"-might choose to disregard this function and endeavour to stick as closely as possible to the linear development of the game's forward-moving trajectory; however, as Triclot emphasises, other players might make this feature central to their experience, "seamlessly re-doing and repeating a sequence until it is deemed satisfactory." ${ }^{47}$ Therefore, while games might engage their players upon linear paths, players might in turn willingly engage their games upon endless repetitions and experimentations. 
23 Even for skilled players disregarding the "quicksave/quickload" function, the experience of a game will more often than not be interrupted by failure and repetition. Thus, while the user's immersion in these games is underlain on large and small scales by a solidly scripted story and cause-and-effect patterns, these can unfold only through a succession of trial, error, and repetition, so that "[a] reconstruction of all the time used on the game would yield a giant tree with numerous forks (the save games), numerous dead ends, and only one path through." ${ }_{48}$ As a result, the player's very participation in the unfolding of the game's progression disrupts the linearity that structures its narrative and visual immersion. While AAA action-adventure games invite their users to look and advance towards the future, be it in terms of narrative development, gameplay actions, or technological innovations, they also immerse them in an experience of confusion, unexpected interruptions, and disrupted progression. As Atkins explains,

[e]verything about contemporary triple-A games, including the frequency of sequels that promise always more than previous incarnations, points toward a future of plural possibility. [...] Our memory of the past always conditions how we anticipate the future, but that future is both predictable and unpredictable, always potential and unknowable until brought into being by the action of playing. ${ }^{49}$ to test out causalities, experimenting with various versions of the same story and eventually building the one that suits her best. As a result, local gameplay challenges become "stories in the making, sketches of different stories." ${ }^{54}$ Even though the linearity of a game's overarching plot can easily feel arbitrary or artificial, on the small-scale level of individual gameplay sequences, it may turn out to be a dynamic space for narrative experimentation and creativity. Some users even decide to completely circumvent the game's intended narrative structures and logics, engaging instead in "transformative play." ${ }^{55}$ This is the case with speedrunners, whose sole aim is to finish 
the game in as little time as possible. These players see images on the screen not as fictional representations of the storyworld, but as physical sets of pixels and paths which allow for the progression of the avatar. They systematically skip through cutscenes and perform only efficient actions, which were painstakingly selected beforehand and trained for in long preparatory sessions. After having carefully tested out cause-and-effect relationships and mapped out the desired sequence of events, they perform their "run" and then post a recording of it on specific websites, where the community might watch and react to it. This sharing of one's performance also exists outside of the speedrunning community, as a growing number of gamers engage in posting or streaming their "playthroughs." Such practices emphasise how the actions performed while playing a videogame can ultimately constitute narrative experiences and even become forms of individual or collaborative storytelling. These small-scale stories, which rely on participation, kinaesthetic immersion, and patterns of repetition, are truly specific to videogames.

\section{BIBLIOGRAPHY}

Atkins, Barry. "What Are We Really Looking at? The Future-Orientation of Video Game Play." Games and Culture 1, no. 2, (2006): 127-40.

Barnabe, Fanny. "Le Speedrun: Pratique Compétitive, Ludique ou Créative? Trajectoire d'un Détournement de Jeu Vidéo Institué en Nouveau Game," Interfaces Numériques 5, no. 3, (2016). http://www.unilim.fr/interfaces-numeriques/3113. <accessed on October 06, 2020>

Bolter, Jay David, and Richard Grusin. Remediation. Understanding New Media. Cambridge [Mass.]: MIT Press Paperback, 2000.

Brooker, Will. "Camera-Eye, CG-Eye: Videogames and the 'Cinematic'." Cinema Journal 48, no. 3, (Spring 2009): 122-28.

Clarkson, Sparky. “Mass Effect 3's Ending Disrespects its Most Invested Players," Kotaku, (April 2013). https://kotaku.com/5898743/mass-effect-3s-ending-disrespects-its-most-invested-players $<$ accessed on October 06, 2020>

Costikyan, Greg. "Where Stories End and Games Begin," Costik, (March 2003). http:// www.costik.com/gamnstry.html <accessed on October 06, 2020>

Elliott, Kamilla. Rethinking the Novel/Film Debate. Cambridge: Cambridge UP, 2003.

Flanagan, Kevin. "Videogame Adaptation." In The Oxford Handbook of Adaptation Studies, edited by Thomas Leitch, 441-55. Oxford: Oxford UP, 2017.

Genvo, Sébastien. “Penser Les Enjeux De La Recherche Sur Les Jeux Vidéo," Revue française des Sciences de l'Information et de la Communication, 20 (2020). http://journals.openedition.org/rfsic/ 9511. <accessed on October 14, 2020>

Grodal, Torben. "Stories for Eye, Ear, and Muscles: Video Games, Media, and Embodied Experiences." In The Video Game Theory Reader, edited by Mark J. P. Wolf, and Bernard Perron, 129-55. New York: Routledge, 2003. 
Hayward, Jennifer. Consuming Pleasures. Active Audiences and Serial Fictions from Dickens to Soap Opera. Lexington: University Press of Kentucky, 1997.

Hagedorn, Roger. “Technology and Economic Exploitation: The Serial as a Form of Narrative Presentation." Wide Angle: A Film Quarterly of Theory, Criticism, and Practice 10, no. 4, (1988): 4-12.

Jenkins, Henry. “Game Design as Narrative Architecture.” In First Person: New Media as Story, Performance, and Game, edited by Noah Wardrip-Fruin, and Pat Harrigan, 118-30. Cambridge [Mass.]: MIT Press, 2004.

Juul, Jasper. "Introduction to Game Time." In First Person. New Media as Story, Performance, and Game, edited by Noah Wardrip-Fruin, and Pat Harrigan, 131-42, Cambridge [Mass.]: MIT Press, 2004.

Kennedy, Alexis. "Spoiler Alert: Game Endings are Harder than You Think. Knowing When to Stop," Eurogamer, (June 2016). http://www.eurogamer.net/articles/2016-06-18-spoiler-alertgame-endings-are-harder-than-you-think <accessed on October 15, 2020>

King, Geoff, and Tanya Krzywinska. "Film Studies and Digital Games." In Understanding Digital Games, edited by Jo Bryce, and Jason Rutter, 112-28. London: SAGE Publications Ltd, 2006.

Chandler, Rafael. Game Writing Handbook. Boston: Charles River Media, 2007.

Ryan, Marie-Laure. Narrative as Virtual Reality 2 - Revisiting Immersion and Interactivity in Literature and Electronic Media. Baltimore: Johns Hopkins University Press, 2015.

Stam, Robert. "Introduction: The Theory and Practice of Adaptation." In Literature and Film. A Guide to the Theory and Practice of Film Adaptation, edited by Robert Stam, and Alessandra Raengo, 1-52. Malden: Blackwell Publishing, 2005.

Triclot, Mathieu. Philosophie des Jeux Vidéo. Paris: Editions La Découverte, 2011.

Walker, John. "What's Right with Mass Effect 3's Ending," Rock, Paper, Shotgun, (March 2012). https://www.rockpapershotgun.com/2012/03/19/whats-right-with-mass-effect-3s-ending/ $<$ accessed on October 15, 2020>

\section{ENDNOTES}

1. See for instance Torben Grodal, "Stories for Eye, Ear, and Muscles: Video Games, Media, and Embodied Experiences," in The Video Game Theory Reader, ed. Mark J. P. Wolf and Bernard Perron (New York: Routledge, 2003).

2. AAA games are the blockbusters of the game industry. They are created with colossal budgets by large development teams in international studios, and they rely on a high degree of profitability, targeting the widest possible audience of players. Along with TV series and Hollywood blockbusters, AAA videogames have now become one of the most prominent ways to immerse wide-scale audiences into visual narrative experiences.

3. Sébastien Genvo, "Penser Les Enjeux De La Recherche Sur Les Jeux Vidéo," Revue française des Sciences de l'Information et de la Communication, 20 (2020): \$32. http://journals.openedition.org/ rfsic/9511. <accessed October 14, 2020>

4. Like the Assassin's Creed franchise, AAA games are sometimes developed and published by the same company-in this case, Ubisoft. But other AAA games, like Mass Effect for instance, can be developed by one or several studios and published by another company-in this case Electronic Arts, who bought the franchise from Microsoft Game Studios in 2007. The publishing company is in charge of the product's marketing and ensures its profitability. 
5. Roger Hagedorn, "Technology and Economic Exploitation: The Serial as a Form of Narrative Presentation," Wide Angle: A Film Quarterly of Theory, Criticism, and Practice 10, no. 4 (1988): 5.

6. Jennifer Hayward, Consuming Pleasures. Active Audiences and Serial Fictions from Dickens to Soap Opera (Lexington: University Press of Kentucky, 1997), 2.

7. Hayward, Consuming Pleasures, 65.

8. Hayward, Consuming Pleasures, 83.

9. Hayward, Consuming Pleasures, 57, 163.

10. Marie-Laure Ryan, Narrative as Virtual Reality 2-Revisiting Immersion and Interactivity in Literature and Electronic Media (Baltimore: Johns Hopkins University Press, 2015), 162-64.

11. Rafael Chandler, Game Writing Handbook (Boston: Charles River Media, 2007), 102.

12. Ryan, Narrative as Virtual Reality 2, 165-66.

13. Hayward, Consuming Pleasures, 83.

14. Before launching into their narrative progression, players of the Mass Effect franchise are asked to choose whether they want to control a male or a female avatar, and to determine some aspects of their personality.

15. John Walker, “What's Right With Mass Effect 3's Ending," Rock, Paper, Shotgun (March 2012). https://www.rockpapershotgun.com/2012/03/19/whats-right-with-mass-effect-3s-ending/ $<$ accessed July 14, 2020>

16. Sparky Clarkson, "Mass Effect 3's Ending Disrespects its Most Invested Players," Kotaku (April 2013). https://kotaku.com/5898743/mass-effect-3s-ending-disrespects-its-most-invested-players $<$ accessed February 08, 2020>

17. Hayward, Consuming Pleasures, 83.

18. Clarkson, "Mass Effect 3's Ending"

19. Jay David Bolter and Richard Grusin, Remediation. Understanding New Media (Cambridge [Mass.]: MIT Press Paperback, 2000), 65.

20. See below.

21. Geoff King and Tanya Krzywinska, "Film Studies and Digital Games," in Understanding Digital Games, ed. Jo Bryce and Jason Rutter (London: SAGE Publications Ltd, 2006), 115.

22. See for instance the review by Sparky Clarkson, quoted above.

23. Greg Costikyan, "Where Stories End and Games Begin," Costik (March 2003). http:// www.costik.com/gamnstry.html <accessed February 08, 2020>

24. Kevin Flanagan, "Videogame Adaptation," in The Oxford Handbook of Adaptation Studies, ed. Thomas Leitch (Oxford: Oxford University Press, 2017), 442.

25. Flanagan, "Videogame Adaptation," 442.

26. For an assertive resolution of this opposition, see for instance Henry Jenkins, "Game Design as Narrative Architecture," in First Person: New Media as Story, Performance, and Game, ed. by Noah Wardrip-Fruin, and Pat Harrigan (Cambridge [Mass.]: MIT Press, 2004), 118-119: "Not all games tell stories. [...] Many games [however] do have narrative aspirations."

27. Robert Stam, "Introduction: The Theory and Practice of Adaptation," in Literature and Film. A Guide to the Theory and Practice of Film Adaptation, ed. Robert Stam and Alessandra Raengo (Malden: Blackwell Publishing, 2005), 23.

28. Will Brooker, "Camera-Eye, CG-Eye: Videogames and the 'Cinematic'," Cinema Journal 48, no. 3, (Spring 2009): 127.

29. Kamilla Elliott, Rethinking the Novel/Film Debate (Cambridge: Cambridge UP, 2003), 83-84.

30. Bolter and Grusin, Remediation, 96-99.

31. Elliott, Rethinking the Novel/Film Debate, 12.

32. Elliott, Rethinking the Novel/Film Debate, 189

33. Elliott, Rethinking the Novel/Film Debate, 190. 
34. Alexis Kennedy, "Spoiler Alert: Game Endings are Harder than You Think. Knowing When to Stop," Eurogamer (June 2016). http://www.eurogamer.net/articles/2016-06-18-spoiler-alertgame-endings-are-harder-than-you-think <accessed February 08, 2020>

35. King and Krzywinska, "Film Studies and Digital Games," 122.

36. King and Krzywinska, "Film Studies and Digital Games," 122.

37. King and Krzywinska, "Film Studies and Digital Games," 122.

38. Hayward, Consuming Pleasures, 65.

39. Ryan, Narrative as Virtual Reality 2, 189.

40. Grodal, "Stories for Eye, Ear, and Muscles: Video Games, Media, and Embodied Experiences," 145.

41. Grodal, "Stories for Eye, Ear, and Muscles," 145.

42. Barry Atkins, "What Are We Really Looking at? The Future-Orientation of Video Game Play," Games and Culture 1, no. 2, (2006): 137

43. Atkins, "Future-Orientation of Video Game Play," 130.

44. Mathieu Triclot, Philosophie des Jeux Vidéo (Paris: Editions La Découverte, 2011), 18-19.

45. Grodal, "Stories for Eye, Ear, and Muscles," 132.

46. Triclot, Philosophie des Jeux Vidéo, 22, my translation.

47. Triclot, Philosophie des Jeux Vidéo, 21, my translation.

48. Jesper Juul, "Introduction to Game Time," in First Person. New Media as Story, Performance, and Game, ed. Noah Wardrip-Fruin and Pat Harrigan (Cambridge [Mass.]: MIT Press, 2004), 138.

49. Atkins, "Future-Orientation of Video Game Play," 139.

50. See Hayward, Consuming Pleasures, 3.

51. Grodal, "Stories for Eye, Ear, and Muscles," 148, original emphasis.

52. Grodal, "Stories for Eye, Ear, and Muscles," 147.

53. Grodal, "Stories for Eye, Ear, and Muscles," 148.

54. Grodal, "Stories for Eye, Ear, and Muscles," 147, original emphasis.

55. Fanny Barnabe, "Le Speedrun: Pratique Compétitive, Ludique ou Créative? Trajectoire d'un Détournement de Jeu Vidéo Institué en Nouveau Game," Interfaces Numériques 5, no. 3, (2016). http://www.unilim.fr/interfaces-numeriques/3113 <accessed February 08, 2020>

\section{ABSTRACTS}

This article seeks to delve further into how videogames rely and/or innovate upon other modes of visual storytelling, thus contribute to an ongoing effort in the field of game studies. This article focuses specifically on AAA action-adventure videogame franchises like Ubisoft's Assassin Creed, Naughty Dog's Uncharted, and BioWare's and Electronic Art's 2007-2012 Mass Effect. Within these, local gameplay missions combine with the development of a large-scale story which unfolds on the screen over hundreds of hours, just as in TV series, and relies on immersive and spectacular images, like in cinematic blockbusters. In their design, these games invite us to follow long linear paths, showing us non-interactive "cinematic" sequences that advance the story, encouraging us to relentlessly move our avatar forward, accumulating power, overcoming obstacles, and carrying the narrative trajectory towards its goal. While a more innovative trend of independent videogames seeks to create and refine a specifically interactive form of narration, the videogame industry continues to channel technological innovation into the making of largescale visually spectacular storyworlds. As a result, these commercial games remain structured by the linear and teleological patterns inherited from traditional modes of storytelling. Nevertheless, the analysis of these games and their designs must not obscure that of the play experience they offer. Specifically in their focus on action, these games open up the possibility for a disrupted experience of linearity during the completion of localised gameplay challenges as 
the player's engagement with images becomes kinaesthetic and her involvement in narrative constructions becomes active. Indeed, by offering a form of immersion based on the player's bodily implication, difficult performance, failure, and repetition, these games allow players to experiment with causalities and hence build their own short narratives: during gameplay sequences, players can save and load, die and retry, and thus go through various versions of small-scale stories, which temporarily obscure or even clash with the large-scale narrative framework scripted by developers. Some players might also engage in creative practices, such as speedrun, which arguably constitute new forms of narrative experiences and storytelling.

\section{INDEX}

Keywords: videogames, interactive storytelling, immersion, narrative experience

\section{AUTHOR \\ CLÉMENCE FOLLÉA}

Clémence Folléa is an Associate Professor at Université de Paris, where she teaches literature, film, and videogame studies in the English department. In her research, she looks at new media and contemporary cultural practices always seeking to study them diachronically and to historicise them. She wrote her PhD on the afterlives of Charles Dickens's work and has published several articles and chapters on the subject. Her current research deals with the possibilities opened by contemporary videogames for epistemological experimentations and ethical experiences.

Université de Paris, LARCA, CNRS, F-75013 Paris, France

clemence.follea@gmail.com 